\title{
A Note On Soft Fuzzy Volterra Spaces
}

\author{
A.Haydar EŞ \\ Department of Mathematics Education, Başkent University, Bağlıca, 06490 Ankara, Turkey \\ haydares@baskent.edu.tr
}

\section{ABSTRACT}

In this paper, the concepts of soft fuzzy $\varepsilon_{r}$-Volterra spaces and soft fuzzy $\varepsilon_{p}$-Volterra spaces are introduced and studied. We will discuss several characterizations of those spaces.

\section{Indexing terms/Keywords}

Soft fuzzy topology; soft fuzzy Volterra spaces; soft fuzzy weakly Volterra spaces; soft fuzzy $\varepsilon_{r}$-Volterra spaces; soft fuzzy $\varepsilon_{p}$-Volterra spaces.

\section{Academic Discipline And Sub-Disciplines}

Mathematics; Topology.

\section{SUBJECT CLASSIFICATION}

Mathematics Subject Classification; 54A40, $03 E 72$.

\section{INTRODUCTION}

Zadeh introduced the fundamental concepts of fuzzy sets in his classical paper [12]. Chang in [1] introduced and developed the concept of fuzzy topological spaces. Since then much attention has been paid to generalize the basic concepts of general topology in fuzzy setting and thus a modern theory of fuzzy topology has been developed. The concept of Volterra spaces have been studied extensively in classical topology in $[3,4]$. The concepts of fuzzy Volterra spaces, fuzzy weakly Volterra spaces and generalized fuzzy Volterra spaces in fuzzy topological spaces are introduced and studied by the authors in [5,6]. The concept of soft fuzzy topological space is introduced by I.U.Tiryaki [10]. The concept of almost P-spaces and almost GP-spaces in soft fuzzy setting was introduced by Es [2] . In this paper, in section 3 , the concepts of soft fuzzy $\varepsilon_{r}$-Volterra spaces and soft fuzzy $\varepsilon_{p}$ - Volterra spaces are introduced and studied.

\section{PRELIMINARIES}

We introduce some basic notions and results that are used in the sequel.

Definition 2.1. [8] Let $\left(X_{s} \tau\right)$ be a fuzzy topological space. Let $\lambda$ be any fuzzy set. Then $\lambda$ is said to be fuzzy $G_{\sigma}$ set if $\lambda=\Lambda_{i=1}^{\infty} \mu_{i}$ where each $\mu_{i}$ is fuzzy open set. The complement of a fuzzy $G_{a}$ set is fuzzy $F_{\sigma}$.

Definition 2.2. [10] Let $X$ be a set, $\mu$ be a fuzzy subset of $X$ and $M \subseteq X$. Then the pair $\left(\mu_{3} M\right)$ will be called a soft fuzzy subset of $X$. The set of all soft fuzzy subsets of $X$ will be denoted by $\operatorname{SF}(X)$.

Proposition 2.3. [10] If $\left(\mu_{j}, M_{j}\right)_{j \in J} \in S F(X)$, then the family $\left\{\left(\mu_{j}, M_{j}\right) \mid j \in J\right\}$ has a meet, that is greatest lower bound, in $(S F(X), \sqsubseteq)$, denoted by $\prod_{j \in J}\left(\mu_{j}, M_{j}\right)$ such that $\prod_{j \in j}\left(\mu_{j}, M_{j}\right)=\left(\mu_{j} M\right)$

where $\mu(x)=\bigwedge_{j \in J} \mu_{j}(x), \forall x \in X$,

$$
M=\bigcap_{j \in J} M_{j}
$$

Definition 2.4. [10] Let $X$ be a non-empty set and the soft fuzzy sets $A$ and $B$ in the form,

$$
\begin{aligned}
& A=\left\{\left(\mu_{s} M\right) \mid \mu(x) \in I^{X_{o}} \forall x \in X_{v} M \subseteq X\right\} \\
& B=\left\{(\lambda, N) \mid \lambda(x) \in I^{X}{ }_{o} \forall x \in X_{0} N \subseteq X\right\}
\end{aligned}
$$

Then,

(i) $A \subseteq B \Leftrightarrow \mu(x) \leq \lambda(x), \forall x \in X_{0} M \subseteq N$.

(ii) $A=B \Leftrightarrow \mu(x)=\lambda(x)_{v} \forall x \in X_{v} M=N$.

(iii) $A^{\circ} \Leftrightarrow 1-\mu(x)_{s} \forall x \in X_{x} X \backslash M$. 
(iv) $A \sqcap B \Leftrightarrow \mu(x) \wedge \lambda(x), \forall x \in X$ and $M \cap N_{x}$ for all $(\mu, M),(\lambda, N) E S F(X)$.

(v) $A \cup B \Leftrightarrow \mu(x) \vee \lambda(x), \forall x \in X$ and $M \cup N_{x}$ for all $(\mu, M),(\lambda, N) \in S F(X)$.

Definition 2.5. [10]

$(0, \emptyset)=\left\{\left(\lambda_{v} N\right) \mid \lambda=0_{s} N=\emptyset\right\}$

$\left(1_{x} X\right)=\left\{\left(\lambda_{x} N\right) \mid \lambda=1_{x} N=X\right\}$

Definition 2.6. [11] For $\left(\mu_{s} M\right) \in S F(X)$ the soft fuzzy set

$$
\left(\mu_{s} M\right)^{\circ}=\left(1-\mu_{s} X \backslash M\right) \text { is called the complement of }\left(\mu_{s} M\right) \text {. }
$$

Definition 2.7. [10] A subset $\tau \subseteq S F(X)$ is called an $S F$-topology on $X$ if

(i) $(0, \emptyset)$ and $(1, X) \in \tau$

(ii) $\left(\mu_{j}, M_{j}\right) \in \tau_{v} j=1,2_{s, n} n \Rightarrow \prod_{j=1}^{n}\left(\mu_{j}, M_{j}\right) \in \tau$

(iii) $\left(\mu_{j}, M_{j}\right), j \in J \Rightarrow \amalg_{j \in j}\left(\mu_{j}, M_{j}\right) \in \tau$. The elements of $\tau$ are called soft fuzzy open,

and those of $\tau^{*}=\left\{\left(\mu_{v} M\right) \mid\left(\mu_{s} M\right)^{s} \in \tau\right\}$ soft fuzzy closed.

If $\tau$ is $S F$-topology on $X$ we call the pair $\left(X_{v} \tau\right) S F$-topological space (in short SFTS).

Definition 2.8. [10] The closure of a soft fuzzy set $\left(\mu_{s} M\right)$ will be denoted by $\overline{\left(\mu_{s} M\right)}$. It is given by

$$
\overline{\left(\mu_{s} M\right)}=\sqcap\left\{\left(\gamma_{s} N\right) \mid\left(\mu_{s} M\right) \subseteq\left(\gamma_{s} N\right),\left(\gamma_{s} N\right) \in \tau\right\} .
$$

Likewise the interior is given by

$$
\left(\mu_{s} M\right)^{s}=\amalg\left\{\left(\gamma_{s} N\right) \mid\left(\gamma_{s} N\right) \in \tau_{s}\left(\gamma_{s} N\right) \subseteq\left(\mu_{s} M\right)\right\} .
$$

Note: $\overline{\left(\mu_{s} M\right)}=\operatorname{cl}\left(\mu_{s} M\right)$ and $\left(\mu_{s} M\right)^{n}=\operatorname{int}\left(\mu_{s} M\right)$.

Definition 2.9. [11] Let $\left(X_{v} \tau\right)$ be a soft fuzzy topological space. Let $\left(\lambda_{v} N\right)$ be a soft fuzzy set in $\left(X_{v} \tau\right)$. Then

(i) $\left(\lambda_{v} N\right)$ is said to be soft fuzzy regular open if $\left(\lambda_{v} N\right)=\operatorname{int}\left(\operatorname{cl}\left(\lambda_{v} N\right)\right)$.

(ii) $\left(\lambda_{0} N\right)$ is said to be soft fuzzy regular closed if $\left(\lambda_{0} N\right)=\operatorname{cl}\left(\operatorname{int}\left(\lambda_{0} N\right)\right)$.

Definition 2.10. [7] A fuzzy topological space $\left(X_{v} \tau\right)$ is called a fuzzy P-space if countable intersection of fuzzy open sets in $\left(X_{v} \tau\right)$ is fuzzy open. That is, every non-zero fuzzy $G_{b}$ set in $\left(X_{v} \tau\right)$, is fuzzy open in $\left(X_{v} \tau\right)$.

Definition 2.11. [8] A fuzzy topological space $\left(X_{v} \tau\right)$ is called a fuzzy almost P-space if for every non-zero fuzzy $G_{a}$ set $\lambda$ in $\left(X_{v} \tau\right)$, int $(\lambda) \neq 0$ in $\left(X_{v} \tau\right)$.

Definition 2.12. 8] A fuzzy topological space $\left(X_{v} \tau\right)$ is called a weak fuzzy P-space if the countable intersection fuzzy regular open sets in $\left(X_{v} \tau\right)$ is a fuzzy regular open set in $\left(X_{v} \tau\right)$.

Definition 2.13. [2] A soft fuzzy topological space $\left(X_{v} \tau\right)$ is called a soft fuzzy weak P-space if the countable intersection soft fuzzy regular open sets in $\left(X_{v} \tau\right)$ is a soft fuzzy regular open set in $\left(X_{v} \tau\right)$. That is, $\prod_{\mathrm{i}=1}^{w}\left(\lambda_{\mathrm{i}}, M_{\mathrm{i}}\right)$ is a soft fuzzy regular open in $\left(X_{v} \tau\right)$, where $\left(\lambda_{\mathrm{i}}, M_{\mathrm{i}}\right)$ 's are soft fuzzy regular open sets in $\left(X_{v} \tau\right)$.

Definition 2.14. [2] A soft fuzzy topological space $\left(X_{v} \tau\right)$ is called a soft fuzzy P-space if countable intersection of soft fuzzy open sets in $\left(X_{v} \tau\right)$ is soft fuzzy open. That is, every non-zero soft fuzzy $G_{\sigma}$ set in $\left(X_{s} \tau\right)$ is soft fuzzy open in $\left(X_{v} \tau\right)$.

Definition 2.15. [2] A soft fuzzy topological space $\left(X_{s} \tau\right)$ is called a soft fuzzy almost P-space if for every non-zero soft fuzzy $G_{0}$ set in $\left(X_{v} \tau\right)$, int $\left(\lambda_{v} M\right) \neq(0, \emptyset)$ in $\left(X_{v} \tau\right)$.

Definition 2.16. [2]A soft fuzzy set $\left(\lambda_{v} M\right)$ in a soft fuzzy topological space $\left(X_{v} \tau\right)$ is called a soft fuzzy nowhere dense if there exists no non-zero soft fuzzy open set $\left(\mu_{s} N\right)$ in $\left(X_{s} \tau\right)$ such that $\left(\mu_{s} N\right) \subseteq \operatorname{cl}\left(\lambda_{s} M\right)$. That is, $\operatorname{int}\left(\operatorname{cl}\left(\lambda_{v} M\right)\right)=\left(0_{s},\right)$.

Definition 2.17. [2] A soft fuzzy set $\left(\lambda_{0} M\right)$ in a soft fuzzy topological space $\left(X_{v} \tau\right)$ is called a soft fuzzy dense if there exists no soft fuzzy closed set $\left(\mu_{s} N\right)$ in $\left(X_{v} \tau\right)$ such that $\left(\lambda_{v} M\right) \subseteq\left(\mu_{s} N\right) \subseteq\left(1_{v}, X\right)$. That is, $\operatorname{cl}\left(\lambda_{v} M\right)=\left(1_{v} X\right)$.

Definition 2.18. [2] A soft fuzzy topological space $\left(X_{v} \tau\right)$ is called a soft fuzzy submaximal space if for each soft fuzzy set $\left(\lambda_{v} M\right)$ in $\left(X_{v} \tau\right)$ such that $\operatorname{cl}\left(\lambda_{v} M\right)=\left(1_{v} X\right)$, then $\left(\lambda_{v} M\right)$ in $\left(X_{s} \tau\right)$. 
Definition 2.19. [2] A soft fuzzy topological space $\left(X_{v} \tau\right)$ is called a soft fuzzy almost GP-space if $\operatorname{int}\left(\lambda_{v} M\right) \neq\left(0_{v} \emptyset\right)$, for each non- zero soft fuzzy dense and soft fuzzy $G_{b} \operatorname{set}\left(\lambda_{v} M\right)$ in $\left(X_{v} \tau\right)$. That is, $\left(X_{v} \tau\right)$ is a soft fuzzy almost GP-space if every non-zero soft fuzzy $G_{b}$ set in $\left(X_{v} \tau\right)$ with $\operatorname{cl}\left(\lambda_{v} M\right)=\left(1_{v} X\right)$, int $\left(\lambda_{v} M\right) \neq\left(0_{v} \emptyset\right)$.

Definition 2.20. [2] A soft fuzzy set $\left(\lambda_{v} M\right)$ in $\left(X_{v} \tau\right)$ is called a soft fuzzy first category set if $\left(\lambda_{v} M\right)=\amalg_{i=1}^{\infty}\left(\lambda_{i}, M_{i}\right)$, where $\left(\lambda_{\mathrm{i}}, M_{\mathrm{i}}\right)$ 's are soft fuzzy nowhere dense in $\left(X_{v} \tau\right)$.

\section{ON SOFT FUZZY VOLTERRA SPACES}

Definition 3.1. Let $\left(\lambda_{v} M\right)$ be a soft fuzzy first category set in soft fuzzy topological space $(\mathrm{X}, \mathrm{T})$. Then $\left(1_{s} X\right)-\left(\lambda_{s} M\right)$ is called a soft fuzzy residual set in $(X, T)$.

Definition 3.2. A SFTS $(\mathrm{X}, \mathrm{T})$ is called a soft fuzzy $\varepsilon_{r}$-Volterra space if $c l\left(\prod_{i=1}^{\mathrm{n}}\left(\lambda_{\mathrm{i}}, M_{\mathrm{i}}\right)\right)=\left(1_{1}, X\right)$, where $\left(\lambda_{\mathrm{i}}, M_{\mathrm{i}}\right)$ 's are soft fuzzy dense and soft fuzzy residual sets in $(X, T)$.

Proposition 3.3. If the SFTS $(X, T)$ is a soft fuzzy $\varepsilon_{r}$-Volterra space, then $\operatorname{int}\left(\cup_{\mathrm{i}=1}^{n}\left(\lambda_{\mathrm{i}}, M_{\mathrm{i}}\right)\right)=\left(0_{0},\right)_{0}$, where the soft fuzzy set $\left(\lambda_{\mathrm{i},}, M_{\mathrm{i}}\right)$ 's are soft fuzzy first category sets such that int $\left(\lambda_{\mathrm{i}}, M_{\mathrm{i}}\right)=\left(0_{0}, \emptyset\right)$ in $(\mathrm{X}, \mathrm{T})$.

Proof. Let $\left(\lambda_{\mathrm{i}}, M_{\mathrm{i}}\right)$ 's $(\mathrm{i}=1,2, \ldots, \mathrm{n})$ be soft fuzzy first category sets such that $\operatorname{int}\left(\lambda_{\mathrm{i}}, M_{\mathrm{i}}\right)=\left(0_{z},\right)$ in $(\mathrm{X}, \mathrm{T})$. Then $\left(\left(1_{s}, X\right)-\left(\lambda_{\mathrm{i} p}, M_{\mathrm{i}}\right)\right)$ 's are soft fuzzy residual sets such that $\left.\mathrm{Cl}\left(\left(1_{0}, X\right)-\left(\lambda_{\mathrm{i}}, M_{\mathrm{i}}\right)\right)\right)=\left(1_{x}, X\right)$ in $(\mathrm{X}, \mathrm{T})$. Since $(\mathrm{X}, \mathrm{T})$ is a soft fuzzy $\varepsilon_{r}$-Volterra space,

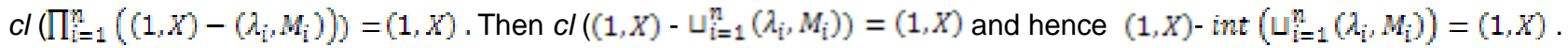
Therefore, we have $\operatorname{int}\left(\cup_{\mathrm{i}=1}^{\mathrm{n}},\left(\lambda_{\mathrm{i}}, M_{\mathrm{i}}\right)\right)=\left(0_{0},\right)$, where $\left(\lambda_{\mathrm{i}}, M_{\mathrm{i}}\right)$ 's are soft fuzzy first category sets such that $\operatorname{int}\left(\lambda_{\mathrm{i},}, M_{\mathrm{i}}\right)=\left(0_{0}, \emptyset\right)$.

Proposition 3.4. Let $(\mathrm{X}, \mathrm{T})$ be a soft fuzzy $\varepsilon_{r}$-Volterra space. Then $(\mathrm{X}, \mathrm{T})$ is a soft fuzzy Volterra space.

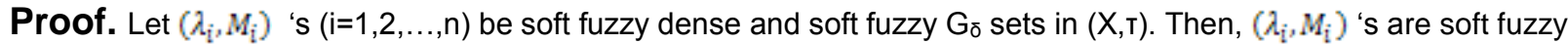
residual sets in $(\mathrm{X}, \mathrm{T})$. This implies that $\left(\lambda_{\mathrm{i},}, M_{\mathrm{i}}\right)$ 's are soft fuzzy dense and soft fuzzy residual sets in $(\mathrm{X}, \mathrm{T})$. Since $(\mathrm{X}, \mathrm{T})$ is a soft fuzzy $\varepsilon_{r}$-Volterra space

$\operatorname{Cl}\left(\prod_{\mathrm{i}=1}^{\mathrm{n}}\left(\lambda_{\mathrm{i}}, M_{\mathrm{i}}\right)\right)=(1, X)$. Hence $(\mathrm{X}, \mathrm{T})$ is a soft fuzzy Volterra space.

Proposition 3.5. If each soft fuzzy nowhere dense set is a soft fuzzy closed set in a soft fuzzy Volterra space (X,T), then $(\mathrm{X}, \mathrm{T})$ is a soft fuzzy $\varepsilon_{r}$-Volterra space.

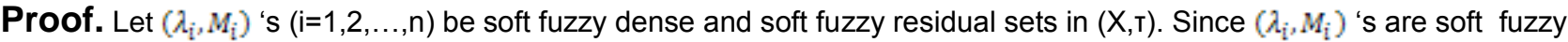

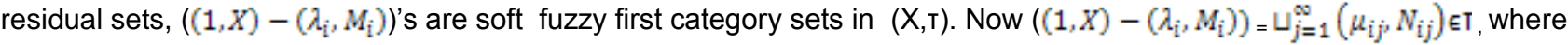
$\left(\mu_{i j p}, N_{i j}\right)$ 's are soft fuzzy nowhere dense sets in $(\mathrm{X}, \mathrm{T})$. From the hypothesis, the soft fuzzy nowhere dense sets $\left(\mu_{\mathrm{ij},} N_{\mathrm{ij}}\right)$ 's are soft fuzzy closed sets and hence $\left(\left(1_{r}, X\right)-\left(\lambda_{\mathrm{i}}, M_{\mathrm{i}}\right)\right)$ 's are soft fuzzy $\mathrm{F}_{6}$ sets in $(\mathrm{X}, \mathrm{T})$. Therefore $\left(\lambda_{\mathrm{i}}, M_{\mathrm{i}}\right)$ 's are soft fuzzy $\mathrm{G}_{\delta}$ sets in $(\mathrm{X}, \mathrm{T})$. Since $(\mathrm{X}, \mathrm{T})$ is a soft fuzzy Volterra space, $c /\left(\prod_{\mathrm{i}=1}^{\mathrm{m}}\left(\lambda_{\mathrm{i}}, M_{\mathrm{i}}\right)\right)=\left(1_{x} X\right)$. Hence $(\mathrm{X}, \mathrm{T})$ is a soft fuzzy $\varepsilon_{r}$-Volterra space.

Definition 3.6. A SFTS $(\mathrm{X}, \mathrm{T})$ is called a soft fuzzy nodec space if every non-zero soft fuzzy nowhere dense set $\left(\lambda_{v} M\right)$ is soft fuzzy closed in $(\mathrm{X}, \mathrm{T})$. That is, if $\left(\lambda_{0} M\right)$ is a soft fuzzy nowhere dense set in $(\mathrm{X}, \mathrm{T})$, then $\left(\left(1_{0}, X\right)-\left(\lambda_{s} M\right)\right) \in \mathrm{T}$.

Proposition 3.7. If the SFTS $(X, T)$ is a soft fuzzy Volterra space and soft fuzzy nodec space, then SFTS $(X, T)$ is a soft fuzzy $\varepsilon_{r}$-Volterra space.

Proof. Let $(\mathrm{X}, \mathrm{T})$ be a soft fuzzy Volterra space and soft fuzzy nodec space and $\left(\lambda_{\mathrm{i}}, M_{\mathrm{i}}\right)$ 's $(\mathrm{i}=1,2, \ldots, \mathrm{n})$ be soft fuzzy dense and soft fuzzy residual sets in $(\mathrm{X}, \mathrm{T})$. Since $\left(\lambda_{\mathrm{i}}, M_{\mathrm{i}}\right)$ 's are soft fuzzy residual sets's are soft fuzzy first category sets in $(\mathrm{X}, \mathrm{T})$. Now $\quad(1, X)-\left(\lambda_{i j}, M_{i}\right)=\cup_{j=1}^{\infty}\left(\mu_{i j}, N_{i j}\right)$, where $\left(\mu_{i j}, N_{i j}\right)$ 's are soft fuzzy nowhere dense sets in $(\mathrm{X}, \mathrm{T})$.Since $(\mathrm{X}, \mathrm{T})$ is a soft fuzzy nodec space, soft fuzzy nowhere dense sets $\left(\mu_{i \bar{p}} N_{\mathrm{i} j}\right)$ 's are soft fuzzy closed in $\left(\mathrm{X}_{0} \mathrm{~T}\right)$. By the Proposition 3.5, $(\mathrm{X}, \mathrm{T})$ is a soft fuzzy $\varepsilon_{r}$-Volterra space.

Proposition 3.8. If the SFTS $(X, T)$ is a soft fuzzy Volterra space and soft fuzzy submaximal space, then $(X, T)$ is a soft fuzzy $\varepsilon_{r}$-Volterra space.

Proof. Obvious. 
Proposition 3.9. If the SFTS $(X, T)$ is a soft fuzzy $\varepsilon_{r}$-Volterra space and soft fuzzy D-Baire space, then $\operatorname{int}\left(\cup_{\mathrm{i}=1}^{\mathrm{n}}\left(\lambda_{\mathrm{i}}, M_{\mathrm{i}}\right)\right)=(0, \emptyset)$, where the $\left(\lambda_{\mathrm{i}}, M_{\mathrm{i}}\right)$ 's are soft fuzzy first category sets in $(\mathrm{X}, \mathrm{T})$.

Proof. Let $(\mathrm{X}, \mathrm{T})$ be a soft fuzzy $\varepsilon_{r}$-Volterra space and soft fuzzy D-Baire space and $\left(\lambda_{\mathrm{i}}, M_{\mathrm{i}}\right)$ 's $(\mathrm{i}=1,2,3, \ldots, \mathrm{n})$ are soft fuzzy first category sets in $(\mathrm{X}, \mathrm{T})$. Since $(\mathrm{X}, \mathrm{T})$ is soft fuzzy $\mathrm{D}$-Baire space, the soft fuzzy first category sets $\left(\lambda_{\mathrm{i}}, M_{\mathrm{i}}\right)$ 's are soft fuzzy nowhere dense sets in $(\mathrm{X}, \mathrm{T})$ and hence $\left(\left(1_{1}, X\right)-\left(\lambda_{\mathrm{i},}, M_{\mathrm{i}}\right)\right)$ 's are soft fuzzy dense sets in $(\mathrm{X}, \mathrm{T})$. Then $\left(\left(1_{0}, X\right)-\left(\lambda_{\mathrm{i}}, M_{\mathrm{i}}\right)\right)$ 's are soft fuzzy dense and soft fuzzy residual sets in $(\mathrm{X}, \mathrm{T})$. By the hypothesis, $c l\left(\prod_{i=1}^{n}\left(\left(1_{0} X\right)-\left(\lambda_{i}, M_{\mathrm{i}}\right)\right)\right)=\left(1_{s} X\right)$. This implies that

$c l\left(\left(1_{v}, X\right)-\cup_{i=1}^{n}\left(\lambda_{i}, M_{i}\right)\right)=\left(1_{x}, X\right)-\operatorname{int}\left(\cup_{i=1}^{n}\left(\lambda_{i}, M_{i}\right)\right)=\left(1_{r} X\right)$. Therefore int $\left(\cup_{i=1}^{n}\left(\lambda_{i}, M_{i}\right)\right)=(0, \emptyset)$, where $\left(\lambda_{i}, M_{i}\right)$ 's are soft fuzzy first category sets in $(X, T)$.

Definition 3.10. Let $(X, T)$ be a SFTS. Then $(X, T)$ is called a soft fuzzy Baire space if int $\left(\left(\cup_{\mathrm{i}=1}^{\mathbb{N}}\left(\lambda_{\mathrm{i}}, M_{\mathrm{i}}\right)\right)=(0, \emptyset)\right.$, where $\left(\lambda_{\mathrm{i}}, M_{\mathrm{i}}\right)$ 's are soft fuzzy nowhere dense sets in $(\mathrm{X}, \mathrm{T})$.

Proposition 3.11. If $\sqcup_{i=1}^{\infty}\left(\lambda_{i}, M_{i}\right)$, where the $\left(\lambda_{i}, M_{i}\right)$ 's are soft fuzzy nowhere dense sets, is a soft fuzzy nowhere dense set in a soft fuzzy Baire space $(\mathrm{X}, \mathrm{T})$, then $(\mathrm{X}, \mathrm{T})$ is a soft fuzzy $\varepsilon_{r}$-Volterra space.

Proof. The proof is similar to Proposition 3.7.

Proposition 3.12. If each soft fuzzy first category set is a soft fuzzy closed set in a soft fuzzy Baire space $(X, T)$, then $(\mathrm{X}, \mathrm{T})$ is a soft fuzzy $\varepsilon_{r}$-Volterra space.

Proof. Let $(X, T)$ be a soft fuzzy Baire space and $\left(\lambda_{\mathrm{i},}, M_{\mathrm{i}}\right)$ 's $(\mathrm{i}=1,2,3, \ldots, \mathrm{n})$ are soft fuzzy dense and soft fuzzy residual sets in $(\mathrm{X}, \mathrm{T})$. Since $\left(\lambda_{\mathrm{i},}, M_{\mathrm{i}}\right)$ 's are soft fuzzy residual sets, $\left(\left(1_{1}, X\right)-\left(\lambda_{\mathrm{i},}, M_{\mathrm{i}}\right)\right)$ 's are soft fuzzy first category sets in $(\mathrm{X}, \mathrm{T})$. By the hypothesis, the soft fuzzy first category sets $\left(\left(1_{r} X\right)-\left(\lambda_{\mathrm{i}}, M_{\mathrm{i}}\right)\right)$ 's are soft fuzzy closed sets in $(\mathrm{X}, \mathrm{T})$ and hence $\left(\lambda_{i}, M_{i}\right)$ 's are soft fuzzy open sets in $(\mathrm{X}, \mathrm{T})$. Since $\left(\lambda_{\mathrm{i},}, M_{\mathrm{i}}\right)$ 's are soft fuzzy dense and soft fuzzy open sets in $(\mathrm{X}, \mathrm{T})$, $\left((1, X)-\left(\lambda_{\mathrm{i}}, M_{\mathrm{i}}\right)\right)$ 's are soft fuzzy nowhere dense sets in $(\mathrm{X}, \mathrm{T})$. Since $(\mathrm{X}, \mathrm{T})$ is a soft fuzzy Baire space, $\operatorname{int}\left(\cup_{i=1}^{n}\left(\left(1_{x}, X\right)-\left(\lambda_{i}, M_{i}\right)\right)\right) \subseteq \operatorname{int}\left(\cup_{i=1}^{\mathbb{N}}\left(\left(1_{x}, X\right)-\left(\lambda_{i}, M_{i}\right)\right)\right)=\left(0_{0}, \emptyset\right)$. That is, $\operatorname{int}\left(\cup_{i=1}^{n}\left(\left(1_{x}, X\right)-\left(\lambda_{i}, M_{i}\right)\right)\right)=\left(0_{x},\right)$ Hence $c l\left(\prod_{\mathrm{i}=1}^{\mathrm{n}}\left(\lambda_{\mathrm{i}}, M_{\mathrm{i}}\right)\right)=\left(1_{0}, X\right)$, where $\left(\lambda_{\mathrm{i}}, M_{\mathrm{i}}\right)$ 's are soft fuzzy dense and soft fuzzy residual sets in $(\mathrm{X}, \mathrm{T})$. Therefore $(\mathrm{X}, \mathrm{T})$ is a soft fuzzy $\varepsilon_{r}$-Volterra space.

Definition 3.13. A SFTS $(\mathrm{X}, \mathrm{T})$ is called a soft fuzzy $\varepsilon_{p}$ - Volterra space if $c l\left(\prod_{\mathrm{i}=1}^{n}\left(\lambda_{\mathrm{i}}, M_{\mathrm{i}}\right)\right)=\left(1_{s} X\right)$, where $\left(\lambda_{\mathrm{i}}, M_{\mathrm{i}}\right)$ s are soft fuzzy pre-open and soft fuzzy $G_{\delta}$ sets in $(X, T)$.

Proposition 3.14. If the SFTS $(X, T)$ is a soft fuzzy $\varepsilon_{p}$ - Volterra space, then Int $\left(\left(\cup_{i=1}^{n g}\left(\lambda_{i}, M_{i}\right)\right)=(0, \emptyset)\right)$, where $\left(\lambda_{\mathrm{i}}, M_{\mathrm{i}}\right)$ 's are soft fuzzy pre-closed and a soft fuzzy $\mathrm{F}_{6}$ sets in $(\mathrm{X}, \mathrm{T})$.

Proof. Let $\left(\lambda_{\mathrm{i},}, M_{\mathrm{i}}\right)$ 's $(\mathrm{i}=1,2,3, \ldots, \mathrm{n})$ be soft fuzzy pre-closed and soft fuzzy $\mathrm{F}_{6}$ sets in $(\mathrm{X}, \mathrm{T})$. Then $\left(\left(1_{1}, X\right)-\left(\lambda_{\mathrm{i}}, M_{\mathrm{i}}\right)\right)$ 's are soft fuzzy pre-open and soft fuzzy $\mathrm{G}_{\delta}$ sets in $(\mathrm{X}, \mathrm{T})$. By the hypothesis, $c l\left(\prod_{\mathrm{i}=1}^{\mathrm{n}}\left(\left(1_{r} X\right)-\left(\lambda_{\mathrm{i}}, M_{\mathrm{i}}\right)\right)\right)=\left(1_{x} X\right)$. Then $c l\left(\left(1_{s} X\right)-\right.$ $\left.\cup_{\mathrm{i}=1}^{\mathrm{n}}\left(\lambda_{\mathrm{i}}, M_{\mathrm{i}}\right)\right)=\left(1_{0}, X\right)-\operatorname{int}\left(\cup_{\mathrm{i}=1}^{\mathrm{n}}\left(\lambda_{\mathrm{i}}, M_{\mathrm{i}}\right)\right)=\left(1_{1}, X\right)$. Therefore, we have $\operatorname{int}\left(\cup_{\mathrm{i}=1}^{\mathrm{n}}\left(\lambda_{\mathrm{i}}, M_{\mathrm{i}}\right)\right)=\left(0_{0}, \emptyset\right)$ where $\left(\lambda_{\mathrm{i},}, M_{\mathrm{i}}\right)$ 's $(i=1,2,3, \ldots, n)$ be soft fuzzy pre-closed and soft fuzzy $F_{6}$ sets in $(X, T)$.

Proposition 3.15. If the SFTS $(\mathrm{X}, \mathrm{T})$ is a soft fuzzy $\varepsilon_{p}$ - Volterra space, then $(\mathrm{X}, \mathrm{T})$ is a soft fuzzy Volterra space.

Proof. Let $\left(\lambda_{\mathrm{i}}, M_{\mathrm{i}}\right)$ 's $(\mathrm{i}=1,2,3, \ldots, \mathrm{n})$ be soft fuzzy dense and soft fuzzy $\mathrm{G}_{\delta}$ sets in $(\mathrm{X}, \mathrm{T})$. Since $\left(\lambda_{\mathrm{i}}, M_{\mathrm{i}}\right)$ 's are soft fuzzy

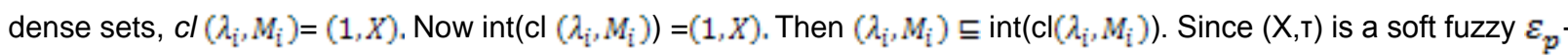
Volterra space and $\left(\lambda_{i}, M_{i}\right)$ 's are soft fuzzy pre-open and soft fuzzy $G_{\delta}$ sets in $(X, T)$,

$c /\left(\prod_{i=1}^{\mathrm{n}}\left(\lambda_{\mathrm{i}}, M_{\mathrm{i}}\right)\right)=\left(1_{i} X\right)$, where $\left(\lambda_{\mathrm{i}}, M_{\mathrm{i}}\right)$ 's are soft fuzzy dense and soft fuzzy $\mathrm{G}_{\delta}$ sets in $(\mathrm{X}, \mathrm{T})$. Hence $(\mathrm{X}, \mathrm{T})$ is a soft fuzzy Volterra space.

Proposition 3.16. If preint $\left(\cup_{\mathrm{i}=1}^{\mathrm{n}}\left(\lambda_{\mathrm{i},}, M_{\mathrm{i}}\right)\right)=\left(0_{0}, \emptyset\right)$ where $\left(\lambda_{\mathrm{i}}, M_{\mathrm{i}}\right)$ 's are soft fuzzy pre-closed sets in a soft fuzzy topological space $(X, T)$, then $(X, T)$ is a soft fuzzy $\varepsilon_{p}$ - Volterra space.

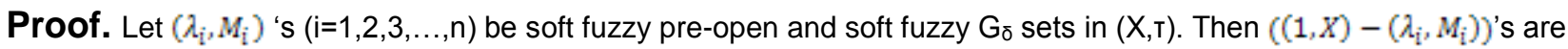
soft fuzzy pre-closed in $(\mathrm{X}, \mathrm{T})$. By the hypothesis , preint $\left(\amalg_{\mathrm{i}=1}^{\mathrm{n}}\left(\left(1_{\mathrm{i}}, X\right)-\left(\lambda_{\mathrm{i}}, M_{\mathrm{i}}\right)\right)\right)=(0, \emptyset)$. This implies that

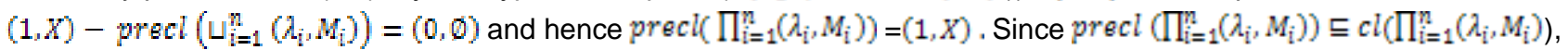
we have $\operatorname{cl}\left(\prod_{\mathrm{i}=1}^{\mathrm{n}}\left(\lambda_{\mathrm{i}}, M_{\mathrm{i}}\right)\right)=\left(1_{\mathrm{r}}, X\right)$. Therefore $\operatorname{cl}\left(\prod_{\mathrm{i}=1}^{\mathrm{n}}\left(\lambda_{\mathrm{i}}, M_{\mathrm{i}}\right)\right)=\left(1_{\mathrm{r}}, X\right)$, where $\left(\lambda_{\mathrm{i},}, M_{\mathrm{i}}\right)$ 's are soft fuzzy pre-open and soft fuzzy $G_{\delta}$ sets in $(X, T)$. Hence $(X, T)$ is a soft fuzzy $\varepsilon_{p}$ - Volterra space. 


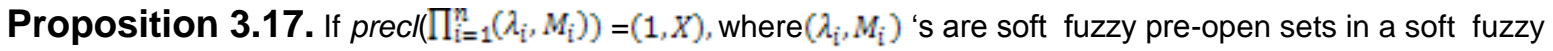
topological space $(\mathrm{X}, \mathrm{T})$, then $(\mathrm{X}, \mathrm{T})$ is a soft fuzzy $\varepsilon_{p}$ - Volterra space.

Proof. The proof is similar to Proposition 3.16.

Proposition 3.18. If $\left(\lambda_{v} M\right)=\amalg_{\mathrm{i}=1}^{\mathrm{n}}\left(\lambda_{\mathrm{i}}, M_{\mathrm{i}}\right)$, where $\left(\lambda_{\mathrm{i}}, M_{\mathrm{i}}\right)$ 's are soft fuzzy pre-closed sets, is a soft fuzzy nowhere dense set in a soft fuzzy topological space $(\mathrm{X}, \mathrm{T})$, then $(\mathrm{X}, \mathrm{T})$ is a soft fuzzy $\varepsilon_{p}$ - Volterra space.

Proof. Suppose that $\left(\lambda_{0} M\right)=\amalg_{\mathrm{i}=1}^{\mathrm{n}}\left(\lambda_{\mathrm{i}}, M_{\mathrm{i}}\right)$, where $\left(\lambda_{\mathrm{i}}, M_{\mathrm{i}}\right)$ 's are soft fuzzy pre-closed sets, and $\left(\lambda_{0} M\right)$ is a soft fuzzy nowhere dense sets in $(\mathrm{X}, \mathrm{T})$. Then preint $\left(\operatorname{prec}\left(\lambda_{0} M\right)\right)=(0, \varnothing)$. Since preint $\left(\lambda_{v} M\right) \subseteq \operatorname{preint}\left(\operatorname{prec}\left(\lambda_{v} M\right)\right)$, we have preint $\left(\lambda_{0}, M\right)=\left(0_{0} \emptyset\right)$. Then preint $\left(\cup_{\mathrm{i}=1}^{\mathrm{n}}\left(\lambda_{\mathrm{i}}, M_{\mathrm{i}}\right)\right)=\left(0_{0} \emptyset\right)$, where $\left(\lambda_{\mathrm{i},}, M_{\mathrm{i}}\right)$ 's are soft fuzzy pre-closed sets in $(\mathrm{X}, \mathrm{T})$. Hence by Proposition 3.16, $(\mathrm{X}, \mathrm{T})$ is a soft fuzzy $\varepsilon_{p}$ - Volterra space.

Proposition 3.19. If each soft fuzzy pre-closed set is a soft fuzzy nowhere dense sets in soft fuzzy $\varepsilon_{r}$-Volterra space $(\mathrm{X}, \mathrm{T})$, then $(\mathrm{X}, \mathrm{T})$ is a soft fuzzy $\varepsilon_{p}$ - Volterra space.

Proof. Obvious.

Proposition 3.20. If a soft fuzzy $\varepsilon_{p}$ - Volterra space $(X, T)$ is a soft fuzzy submaximal space, then $(X, T)$ is a soft fuzzy $\varepsilon_{r}$-Volterra space.

Proof. Immediate from the definitions.

Proposition 3.21. If each soft fuzzy nowhere dense set is soft fuzzy closed set in a soft fuzzy $\varepsilon_{p}$-Volterra space $(\mathrm{X}, \mathrm{T})$, then $(\mathrm{X}, \mathrm{T})$ is a soft fuzzy $\varepsilon_{r}$-Volterra space.

Proof. It is clear from the definitions.

Proposition 3.22. If a soft fuzzy $\varepsilon_{p}$ - Volterra space $(\mathrm{X}, \mathrm{T})$ is a soft fuzzy nodec space, then $(\mathrm{X}, \mathrm{T})$ is a soft fuzzy $\varepsilon_{r}$ Volterra space.

Proof. Let $(X, T)$ be a soft fuzzy $\varepsilon_{p}$ - Volterra space and a soft fuzzy nodec space.Since $(X, T)$ is a soft fuzzy nodec space, each soft fuzzy nowhere dense set is a soft fuzzy closed set in (X,T). By Proposition 3.21, (X,T) is a soft fuzzy $\varepsilon_{r}$ Volterra space.

\section{REFERENCES}

1. Chang, C. L., Fuzzy topological spaces, J.Math.Anal.,Vol. 24, 1968, 182-190.

2. Eş,A.H., On soft fuzzy almost P-spaces, International Journal of Mathematical Archive,7(5)(2016), 1-5.

3. Gauld, D., Greenwood, S., Piotrowski,Z., On Volterra spaces II, Ann. New York Acad.Sci., 806(1996),169-173.

4. Gauld, D., Piotrowski, Z., On Volterra spaces, Far East J.Math.Sci., 1(1993),209-214.

5. Thangaraj, G., Soundararajan,S., Generalized fuzzy Volterra spaces, Annals of Fuzzy Mathematics and Informatics , 11(4)(2016),633-644.

6. Thangaraj, G., Soundararajan,S., On fuzzy Volterra spaces, J.Fuzzy Math., 21(4)(2013), 895-904.

7. Thangaraj, G., Anbazhagan, C., Some remarks on fuzzy P-spaces, Gen.Math.Notes, 26(1) (2015), 8-16.

8. Thangaraj, G., Anbazhagan, C., Vivakanandan, P., On fuzzy P-spaces, weak fuzzy P-spaces and fuzzy almost P-spaces, Gen.Math.Notes, 18(2) (2013), 128-139.

9. Thangaraj, G., Anbazhagan, C., On fuzzy almost GP-spaces, Annals of Fuzzy Mathematics and Informatics, 10(5) (2015), 727-736.

10. Tiryaki, I.U., Fuzzy sets over the posets I, Hacettepe Journal of Mathematics and Statistics, 37(2) (2008), 143166.

11. Visalakshi, V., Uma, M.K., Roja, E., On soft fuzzy G G $_{\bar{\delta}}$ pre continuity in soft fuzzy topological space, Annals of Fuzzy Mathematics and Informatics, 8(6) (2014), 921-939.

12. Zadeh, L.A., Fuzzy sets, Information and Control, 8 (1965), 338-353. 